\title{
HEMATOLOGIA DE TILÁPIAS CONSUMINDO DIETA CONTENDO PALMA E PROBIÓTICO
}

\section{HEMATOLOGIA DE TILÁPIAS CONSUMINDO DIETA CONTENDO PALMA E PROBIÓTICO}

\author{
Keisyara Bonfim dos SANTOS $^{1 *}$, William Cristiane Teles TONINI ${ }^{1}$, Ricardo Luiz WAGNER ${ }^{1}$, Antônio \\ NASCIMENTO ${ }^{2}$, Samara Rocha Mendes dos SANTOS $^{1}$, Wenderson Nascimento BESSA ${ }^{1}$, Ubiratan Ferreira CRUZ ${ }^{1}$, \\ Thalis Alves NOGUEIRA ${ }^{1}$ \\ ${ }^{1}$ Departamento de Ciências Humanas e Suas Tecnologias, \\ Universidade do Estado da Bahia-UNEB. \\ ${ }^{2} 2^{a}$ Superintendência Regional da Companhia de Desenvolvimento dos Vales do São Francisco e Parnaíba - \\ CODEVASF \\ *e-mail: keisyara_santos@hotmail.com
}

Resumo - O objetivo do trabalho foi avaliar a inclusão de níveis crescentes de Saccharomyces boulardii na dieta, sobre os parâmetros hematológicos de tilápia do Nilo alimentadas com ração suplementada com palma. Pós-larvas de tilápia $(1,8 \pm 0,20 \mathrm{~g})$ foram distribuídas aleatoriamente em 16 hapas (54 1) acondicionadas em quatro caixas de água (1000 1) numa densidade de 20 peixes/hapa. O delineamento utilizado foi em blocos casualizados com 4 tratamentos e 4 repetições, sendo os níveis de inclusão do probiótico liofilizado de: T1(tratamento1): 0; T2 1,25; T3 2,5 e T4 5 mg/kg em ração de $42 \%$ de proteína bruta contendo $11 \%$ de farelo de palma. As análises estatísticas foram realizadas com o auxílio do software SAS. Após 45 dias, 3 peixes de cada unidade experimental foram capturados aleatoriamente para coleta de $0,5 \mathrm{ml}$ de sangue para determinação das varáveis leucocitárias, trombócitos e glicose. O T1 promoveu maior número de neutrófilos. T2 e T3 apresentaram mesmo resultado para todas as variáveis leucocitárias. T4 promoveu diminuição do percentual de trombócitos e aumento de linfócitos. A suplementação de $2,5 \quad \mathrm{mg} / \mathrm{kg}$ apresentou menor nível de glicose. A inclusão de $5 \mathrm{mg} / \mathrm{kg}$ de levedura pode ser feita em dietas para tilápias do Nilo contendo palma.

Palavras-Chave: Alimento alternativo; glicemia; Parâmetros sanguíneos; Saccharomyces boulardii.

\begin{abstract}
The objective of the work was to evaluate the inclusion of increasing levels of Saccharomyces boulardii in the diet, on the hematological parameters of Nile tilapia fed with diet supplemented with palm. Tilapia post-larvae $(1.8 \pm 0.20 \mathrm{~g})$ were randomly distributed in 16 hapas (54 1) stored in four water boxes (1000 1) at a density of 20 fish / hapa. The design used was in randomized blocks with 4 treatments and 4 repetitions, with the inclusion levels of the lyophilized probiotic being: T1 (treatment1): 0 ; T2 1.25; T3 2.5 and T4 $5 \mathrm{mg} / \mathrm{kg}$ in a diet of $42 \%$ crude protein containing $11 \%$ palm bran. Statistical analyzes were performed with the aid of the SAS software. After 45 days, 3 fish from each experimental unit were randomly captured to collect $0.5 \mathrm{ml}$ of blood to determine leukocyte variables, thrombocytes and glucose. T1 promoted a greater number of neutrophils. T2 and T3 showed the same result for all leukocyte variables. T4 promoted a decrease in the percentage of thrombocytes and an increase in lymphocytes. The supplementation of $2.5 \mathrm{mg} / \mathrm{kg}$ showed a lower glucose level. The inclusion of $5 \mathrm{mg} / \mathrm{kg}$ of yeast can be made in diets for Nile tilapia containing palm.
\end{abstract}

Key words: Alternative food; blood glucose; Blood parameters; Saccharomyces boulardii. 


\section{ARTIGO REVISTA BRASILEIRA DE ENGENHARIA DE PESCA}

\section{Introdução}

No Brasil a aquicultura vem se estabelecendo como uma das atividades mais promissoras do agronegócio, com forte tendência para ultrapassar a produção de bois, suínos e frangos na próxima década, sendo a piscicultura o ramo dessa produção de maior destaque (Araujo et al., 2015; Santo et al., 2016).

No nordeste brasileiro a tilápia do Nilo é o peixe mais produzido pela piscicultura. Essa espécie é rústica, com fácil adaptação aos diferentes sistemas produtivos desenvolvidos na região, aceita ração desde as primeiras fases de vida e atinge alta produtividade, com boa aceitação no mercado consumidor (Brito et al., 2014; Vidal, 2016).

A produção de grãos, como soja e milho, no Nordeste não é suficiente para produção de rações como na região Centro-Oeste do Brasil, o que torna o valor desse insumo elevado para os produtores. A depender do tipo de sistema de produção adotado, as rações podem representar de $40 \%$ a $70 \%$ dos custos totais produtivos, sendo na produção intensiva de tilápias o item de maior custo (Kubitza, 1999).

O farelo de palma é uma das alternativas com potencial para substituir parcialmente rações comerciais para monogástricos graças ao seu valor nutricional, elevada palatabilidade e produção de biomassa. A palma forrageira é uma cactácea adaptada às condições edafoclimáticas do Nordeste, que vem sendo produzida e utilizada tradicionalmente como alimento base para a alimentação de ruminantes nos períodos de seca (Furuya, 2001; Reveles-Hernández et al., 2010; Galvão Júnior, 2014; Frota et al., 2015; Macedo et al., 2015).

De acordo com dados do Censo Agropecuário do Instituto Brasileiro de Geografia e Estatística (IBGE), em 2017 o Brasil produziu 3.581.469 toneladas de Palma forrageira sendo a região nordeste responsável por 3.567.792 toneladas (IBGE, 2017).

Segundo Oliveira et al. (2013) a tilápia do Nilo apresenta uma baixa digestibilidade de diferentes variedades da palma, sendo importante a adoção de estratégias que favoreçam um melhor aproveitamento desse ingrediente pela espécie.

Em produções de peixes, as elevadas densidades de estocagem, as manipulações constantes dos organismos durante as rotinas de manejo, a alimentação e a qualidade da água podem ocasionar estresse nos organismos (Mundim et al., 2016). O estresse torna os peixes vulneráveis às doenças, provoca problemas fisiológicos que alteram a eficiência do sistema imune interferindo nos mecanismos de defesa orgânica do organismo (Cavalheiro, 2014; Schach et al., 2015).

Uma das estratégias intensamente utilizada para prevenir e tratar doenças na piscicultura foram os antibióticos, entretanto, desde 2006, sua utilização é proibida por gerar resistência aos microrganismos e manter resíduos na carne, que interferem na saúde dos consumidores. Uma das alternativas para substituir os antibióticos que vem despertando o interesse de pesquisadores é a incorporação de probióticos nas rações (Azevedo et al., 2016; Delmachio, 2018).

As leveduras são um dos grupos de microrganismos probióticos com potencial para a inclusão em rações para organismos aquáticos. Esses organismos são fontes de vitaminas do complexo B, minerais como o fósforo, potássio, cálcio, magnésio, selênio e zinco ricos em fatores de crescimento que são estimulantes de bactérias benéficas e antibióticos naturais (Pardo-Gamboa et al., 2011), além disso, as leveduras são capazes de se desenvolver e utilizar como substrato para seu metabolismo os polissacarídeos abundantes na palma forrageira (Araújo et al., 2008).

Na produção de peixes, o acompanhamento do hemograma é uma ferramenta promissora para o diagnóstico do estado de higidez dos animais (Falcon et al., 2008). Entre as análises hematológicas que podem ser avaliadas durante o fornecimento de diferentes dietas destacam-se o hematócrito e o eritrograma que estão associados à capacidade de transporte de oxigênio, o leucograma que permite o diagnóstico de processos infecciosos e a glicemia que através dos níveis 
de glicose pode indicar situações de estresse (Silveira, Logato \& Pontes,2009; Silva, 2012; Costa et al., 2014).

Pouco se conhece sobre a influência da inclusão de Saccharomyces boulardii em rações suplementadas com palma sobre os parâmetros hematológicos de juvenis de tilápia-do-Nilo.

Diante disso, o objetivo do presente trabalho foi avaliar a inclusão de níveis crescentes de Saccharomyces boulardii na dieta, sobre os parâmetros hematológicos de pós-larvas de tilápias do Nilo alimentadas com ração suplementada com palma.

\section{Material e Métodos}

O experimento foi realizado no laboratório de siluriformes do Centro Integrado de Recursos Pesqueiros e Aquicultura - CIRPA de Xique-Xique/BA da Companhia de Desenvolvimento dos Vales do São Francisco e Parnaíba - CODEVASF- $2^{\text {a }}$ Superintendência Regional - SR nos meses de outubro e novembro de 2018 durante 45 dias.

Foram utilizadas 320 pós-larvas de tilápia do Nilo (Oreochromis niloticus) induzidas sexualmente para macho, com o peso e comprimento médio de $1,8 \pm 0,20$ gramas e $38 \pm 2,3$ milímetros respectivamente obtidas de produção do centro de realização do trabalho. Foram distribuídos aleatoriamente em 16 hapas de 54 litros numa densidade de 2,7 peixes/L (20 peixes/ hapa) sendo considerada para o cálculo dessa densidade as recomendações da Embrapa de que a cada 1000 litros de água deve-se estocar 150 peixes (6,6 peixes/L). As hapas foram mantidas em quatro tanques circulares de polietileno de 1000 litros (4 hapas/tanque) dispostos como um sistema fechado de recirculação de água e aeração artificial pelo modelo Venturi.

O delineamento experimental foi inteiramente casualizado com quatro tratamentos e quatro repetições sendo: $\mathrm{T} 1$ (tratamento 1): zero $\mathrm{mg}$ de probiótico liofilizado por $\mathrm{kg}$ de ração, T2: 1,25 $\mathrm{mg} / \mathrm{kg}$, T3: $2,5 \mathrm{mg} / \mathrm{kg}$ e T4: $5 \mathrm{mg} / \mathrm{kg}$, sendo esses níveis estabelecidos baseados em valores encontrados na literatura para levedura. Foram elaboradas dietas isoprotéicas $(42 \%$ de proteína bruta) e isoenergérticas $(3600 \mathrm{kcal} / \mathrm{kg}$ ) com uma substituição de $11 \%$ do peso, por farelo de palma (HANNAH et al., 2016), variando apenas o probiótico utilizado (levedura Saccharomyces boulardii) adquirido em comércio local. Na tabela 1, estão apresentados os ingredientes presentes nas dietas experimentais.

Tabela 1. Composição Percentual Dos Ingredientes Da Dieta Controle.

\begin{tabular}{lc}
\hline Ingrediente & $\%$ \\
\hline Ração comercial em pó (42\% PB) & 74,35 \\
Farelo de palma & 11,00 \\
Fubá de milho & 9,70 \\
Amido de milho & 4,80 \\
Suplemento vitamínico (Premix) & 0,15 \\
\hline Total & 100,0 \\
\hline
\end{tabular}

A palma utilizada foi da espécie Opuntia ficus-indica da variedade comum obtida em propriedade rural da região. Para a sua inclusão na ração essa inicialmente foi cortada manualmente, seca ao ar livre e em estufa artesanal durante 48 horas, em seguida foi triturada em máquina forrageira e peneirada para obtenção do farelo.

Para a preparação da ração, os ingredientes (tabela 1) foram misturados e umedecidos com água a $24^{\circ} \mathrm{C}$. Em seguida a mistura foi peletizada em máquina de moer carne automática e seca em temperatura ambiente por $48 \mathrm{~h}$. Após a secagem os peletes foram triturados manualmente para que apresentasse granulometria compatível com à abertura da boca das pós-larvas, em seguida 
acondicionada em embalagens plástica identificadas e armazenada em freezer a $18^{\circ}$ durante todo o período experimental sendo retirada somente pouco tempo antes de sua utilização.

Os animais foram introduzidos no sistema proposto, por um período inicial de oito dias, antes da alimentação com as dietas teste, para adaptação às instalações e ao manejo alimentar das refeições diárias.

O sistema de alimentação utilizado foi de quatro refeições diárias às $9 \mathrm{~h}, 11 \mathrm{~h}, 14 \mathrm{~h}, 16 \mathrm{~h}$ manualmente na forma ad libitum, com coleta de possíveis sobras por sifonamento, trinta minutos após o fornecimento.

Os parâmetros de qualidade de água oxigênio, $\mathrm{pH}$ e temperatura foram aferidos em dias alternados com sonda multiparâmetro Hannah Hl 98194, amônia e nitrito semanalmente com kits colorimétricos próprios para água doce da Labcon Test específicos para cada variável.

Após 45 dias de alimentação, três animais de cada unidade experimental foram aleatoriamente separados, anestesiados por imersão em benzocaína $0,5 \mathrm{mg} / \mathrm{L}$, e logo em seguida, coletado $0,5 \mathrm{~mL}$ de sangue via punção cardíaca, com seringas heparinizadas. Foram então realizadas avaliações hematológicas de leucócitos, trombócitos e glicose para investigar a influência do aditivo como mitigador dos indicadores de estresse.

Para a contagem de leucócitos foi utilizada a metodologia proposta por Berra et al. (1993), onde a contagem dos leucócitos totais ocorreu de forma direta em câmara de Neubauer. A contagem diferencial (neutrófilos, linfócitos, monócitos, eosinófilos e basófilos) ocorreu através da confecção de esfregaços sanguíneos corados pancromaticamente pelo método de Rosenfeld (1947), onde foram contadas 100 células em cada extensão sanguínea para o estabelecimento do percentual de cada componente celular com auxílio de microscópio estereoscópio com lente de 40x. No mesmo esfregaço sanguíneo usado na diferencial de leucócitos, foi quantificado o número de trombócitos (por $\mu \mathrm{L}$ ) utilizando-se da seguinte fórmula:

\section{Trombócitos $=\underline{\left.\mathrm{n}^{\mathrm{o}} \text { trombócitos na extensão } \times \mathrm{n}^{\mathrm{o}} \text { de eritrócitos (por } \mu \mathrm{L}\right)}$ 2000 eritrócitos contados na extensão sanguínea}

Também foi feita a análise glicêmica, sendo que a determinação dos níveis plasmáticos de glicose ocorreu através do método direto, com auxílio de kit G-tech life.

Os resultados das variáveis hematológicas avaliadas foram submetidos à análise de variância pelo pacote computacional SAS Institute (2010). Para as variáveis quantitativas que apresentaram homogeneidade e distribuição normal leucócitos (percentual de distribuição celular: neutrófilos, linfócitos, trombócitos) e glicose e foram aplicadas ANOVA ao nível de probabilidade de 5\%. Para as variáveis quantitativas que não apresentaram distribuição normal (percentual de distribuição celular - monócitos, eosinófilos, basófilos) foi utilizado o teste não paramétrico de Kruskal-Wallis $(\mathrm{P}<0,05)$.

\section{Resultados e Discussão}

Os valores médios da qualidade de água, em relação ao oxigênio dissolvido $(5,05 \mathrm{mg} / \mathrm{L} \pm$ $0,42), \mathrm{pH}(6,8 \pm 0,38)$, temperatura $\left(28,46^{\circ} \pm 0,47\right)$, amônia total $(0,25 \mathrm{mg} / \mathrm{L} \pm 0,00)$, amônia tóxica $(0$ $\mathrm{mg} / \mathrm{L} \pm 0)$ e nitrito $(0,58 \mathrm{mg} / \mathrm{L} \pm 038)$ foram considerados adequados ao cultivo da espécie segundo Sá (2012). A suplementação com $S$. boulardii não ocasionou mortalidade durante o período de experimento em nenhum dos tratamentos.

Na tabela 2 estão apresentados os percentuais médios de trombócitos, linfócitos, neutrófilos, monócitos, eosinófilos e basófilos de pós-larvas de tilápias do Nilo alimentadas com ração suplementada com palma e níveis crescentes de levedura. 


\section{ARTIGO}

\section{REVISTA BRASILEIRA DE ENGENHARIA DE PESCA}

Observou-se efeito significativo $(\mathrm{P}<0,05)$ para o $\mathrm{T} 4(5 \mathrm{mg} / \mathrm{kg}$ de levedura $)$ no menor percentual de trombócitos e maior de linfócitos e para o T1 (sem inclusão de levedura) no maior percentual de neutrófilos como pode ser observado na tabela 2.

Tabela 2. Valores médios e coeficiente de variação dos Parâmetros hematológicos da série branca de tilápias do Nilo (O. niloticus), alimentadas com dieta suplementada com palma e diferentes níveis de leveduras.

\begin{tabular}{ccccccc}
\hline Tratamento & \multicolumn{5}{c}{ Variável (\%) } \\
\hline & Trombócitos & Linfócitos & Neutrófilos & Monócitos & Eosinófilos & Basófilos \\
\cline { 2 - 7 } T1 & $37,0^{\mathrm{a}}$ & $33,0^{\mathrm{a}}$ & $26,0^{\mathrm{a}}$ & $2,0^{\mathrm{a}}$ & $1,0^{\mathrm{a}}$ & $0,0^{\mathrm{a}}$ \\
T2 & $38,2^{\mathrm{a}}$ & $36,0^{\mathrm{a}}$ & $22,5^{\mathrm{b}}$ & $2,0^{\mathrm{a}}$ & $1,0^{\mathrm{a}}$ & $0,3^{\mathrm{a}}$ \\
T3 & $37,5^{\mathrm{a}}$ & $35,5^{\mathrm{a}}$ & $22,0^{\mathrm{b}}$ & $3,0^{\mathrm{a}}$ & $1,5^{\mathrm{a}}$ & $0,0^{\mathrm{a}}$ \\
T4 & $34,6^{\mathrm{b}}$ & $39,7^{\mathrm{b}}$ & $21,0^{\mathrm{b}}$ & $3,0^{\mathrm{a}}$ & $1,7^{\mathrm{a}}$ & $0,0^{\mathrm{a}}$ \\
CV $(\%)$ & 9,60 & 8,83 & 6,34 & 2,82 & 2,01 & 1,16 \\
\hline
\end{tabular}

*Análise de similaridade onde letras iguais significam médias sem diferença significativa.

Os trombócitos são as células sanguíneas menos estudadas, desse modo pouco se conhece a respeito de sua função. Em peixes essas células influenciam na coagulação sanguínea e podem estar relacionadas com o sistema de defesa em processos inflamatórios e de fagocitose, por conta disso, sua contagem e distribuição está associada aos leucócitos, sendo essa associação conhecida como a de células sanguíneas de defesa orgânica (Matushima \& Mariano, 1996; Azevedo et al., 2006). Os trombócitos foram contados juntamente com os diversos tipos de leucócitos, entretanto, eles não foram considerados como célula de linhagem leucocitária (Matushima \& Mariano 1996).

A liberação de hormônios glicocorticoides durante situações de estresse acarreta a ocorrência da glicogenólise e a gliconeogênese hepática. Essa condição reflete de forma quantitativa sobre o número de trombócitos, pois ocasiona uma trombocitose (elevação do número de trombócitos ou plaquetas), decorrente da contração esplênica, em que o baço sequestra de $1 / 4$ a $2 / 3$ do total das plaquetas para circulação (Pickering 1981, Wendelaar Bonga 1997; Silva et al., 2012).

A suplementação de $5 \mathrm{mg} / \mathrm{kg}$ de $S$. boulardii reduziu o percentual de trombócitos circulantes quando comparado as inclusões de $1,25 \mathrm{mg} / \mathrm{kg}$ e $2,5 \mathrm{mg} / \mathrm{kg}$. Uma das possíveis explicações para essa redução é que esse percentual de inclusão da levedura tenha induzido uma migração dos trombócitos circulantes na corrente sanguínea para algum tecido acometido por algum agente estressor.

Reque et al. (2010), avaliando a resposta inflamatória e os parâmetros hematológicos da tilápia do Nilo recebendo ração suplementada com levedura $S$. cerevisiae autolisada e parede celular e submetidas ao estímulo inflamatório com Aeromonas hydrophila inativada, sugeriram o recrutamento de leucócitos e trombócitos do compartimento sanguíneo para o foco inflamatório o que proporcionou um aumento inespecífico da resposta inflamatória aguda, com maior acúmulo de defesa das células no foco da lesão.

Os neutrófilos são as células de defesa responsáveis pela morte e digestão de bactérias através da fagocitose, atuam na linha de frente do sistema imunológico do organismo contra agentes invasores (Falcon et al., 2008).

De acordo com Silva et al. (2012); Rijnberk \& Mol (1997) em situações de estresse a liberação de cortisol interfere na fagocitose e migração de leucócitos para a região inflamada gerando uma neutrofilia (aumento do número de neutrófilos no sangue), uma vez que os neutrófilos deixam de migrar para os tecidos e permanecem por maior tempo circulantes.

No tratamento sem adição de levedura, o maior percentual deste tipo de célula pode induzir que os peixes estavam com sua resistência afetada por algum agente estressor, uma vez que em condições de estresse os neutrófilos permanecem maior tempo circulantes. Nessa condição, a ausência de suplementação da levedura pode ter tornado os peixes mais vulneráveis a esses agentes, 


\section{ARTIGO REVISTA BRASILEIRA DE ENGENHARIA DE PESCA}

por não induzir a resposta imune. De acordo com Silveira e Rigores (1989), peixes expostos a estímulos estressantes, como o confinamento experimental, apresentam elevação do número de neutrófilos circulantes.

A adição de pequena quantidade de levedura no T2 foi o suficiente para reduzir o percentual de neutrófilos circulantes na corrente sanguínea dos peixes que ingeriram a dieta desse tratamento mantendo-se esse padrão de redução nas análises dos T3 e T4, sugerindo que a presença da levedura, mesmo em pequenas quantidades, já é responsável pela melhora da resistência das tilápias induzindo uma diminuição dos neutrófilos na circulação e possivelmente estimulando sua migração para os tecidos.

De acordo com Costa (2004) e Souza et al. (2011), as leveduras vivas (forma ativa) podem ser fornecidas aos animais na dieta como probiótico, uma vez que, esse grupo de organismo não coloniza naturalmente o epitélio intestinal, entretanto, possuem a capacidade de se multiplicar e transitar junto com o bolo alimentar diminuindo a atuação de microrganismos potencialmente patogênicos e mantendo a saúde do trato gastrointestinal. Por exclusão competitiva as leveduras vivas evitam que populações de enterobactérias se fixem no aparelho digestivo.

Os linfócitos são as células mais abundantes entre os leucócitos do organismo, são responsáveis pela produção de anticorpos e resposta celular humoral, nos tecidos em reações de defesa são as células mais abundantes junto com os macrófagos. No sangue dos peixes essa predominância ainda não está bem elucidada, o que se sabe é que em situações de estresse o número de linfócitos na circulação diminui (Silva et al., 2012).

O maior percentual de linfócitos para a inclusão de $5 \mathrm{mg} / \mathrm{kg}$ de levedura pode estar associado a uma maior resistência dos organismos, uma vez que em condições de estresse essas células encontram-se em menores valores na circulação sanguínea. Apesar de não terem ocorridos diferenças significativas entre os tratamentos com menores níveis de inclusão do probiótico e o tratamento sem levedura, o menor valor de linfócitos na ausência de Saccharomyces pode estar associada a interferências na homeostase dos peixes.

Jatobá et al. (2008), avaliando o potencial probiótico de L. plantarum na ração de tilápias do Nilo, observaram que na contagem diferencial de leucócitos, os peixes alimentados com ração suplementada com L. plantarum apresentaram os maiores números de linfócitos circulantes. Segundo esses autores essa suplementação probiótica pode ter induzido a produção ou liberação de leucócitos totais e de linfócitos circulantes, resultados semelhantes ao observado no presente trabalho.

Signor et al. (2010) avaliando a influência da suplementação de levedura autolisada e zinco e suas relações nas dietas, sobre os parâmetros hematológicos de alevinos de tilápias do Nilo em diferentes temperaturas, observaram alterações significativas nas células de defesa dos peixes com linfopenia (redução do número de linfócitos no sangue) independente da suplementação ou não de levedura autolisada e zinco. Sendo a suplementação de $4,0 \mathrm{mg} / \mathrm{kg}$ de levedura e $400 \mathrm{mg} / \mathrm{kg}$ de zinco as que promoveram maiores porcentagens de linfócitos

Nas produções de peixes fatores como a temperatura as manipulações dos animais inclusive durante o transporte são consideradas agentes estressores que interferem nos níveis de glicose plasmática (Urbinati et al., 2004).

Na tabela 2 estão apresentados os valores de glicose $(\mathrm{mg} / \mathrm{dL})$ que indicam o nível de estresse sofrido pelas tilápias do Nilo alimentadas com ração suplementada com palma e níveis crescentes de levedura. Houve diferenças significativas $(\mathrm{P}<0,05)$ no tratamento 3 , quando comparado ao tratamento 1 sem a inclusão da levedura.

Tabela 3. Valores médios, desvios padrão e coeficiente de variação da glicemia de tilápias do Nilo (O. niloticus), alimentadas com diferentes níveis de Levedura em rações com inclusão de $11 \%$ de palma. 


\section{ARTIGO REVISTA BRASILEIRA DE ENGENHARIA DE PESCA}

\begin{tabular}{ccc}
\hline Tratamento & Glicose & CV \\
\hline T1 & $22,0 \pm 12,2 \mathrm{a}$ & 0,56 \\
T2 & $19,25 \pm 3,3 \mathrm{ab}$ & 0,17 \\
T3 & $11,5 \pm 2,0 \mathrm{~b}$ & 0,18 \\
T4 & $24,7 \pm 11,1 \mathrm{a}$ & 0,45 \\
\hline
\end{tabular}

\#Letras iguais médias sem diferença significativa, letras diferentes, médias com diferença significativa, segundo programa estatístico SAS 6.0.

No tratamento 3 a quantidade $2,5 \mathrm{mg}$ de levedura pode ter favorecido a colonização direta desses microrganismos no cólon intestinal, sem causar nenhum distúrbio metabólico relacionado a microflora existente nessa região do intestino que ocasionasse algum estresse que interferisse diretamente nos valores da glicemia. Diferente do tratamento 1 sem a inclusão da levedura, onde algum agente estressor influenciou nos níveis de cortisol e consequentemente na glicose ou por distúrbio metabólico envolvendo a digestão da palma pode ter elevado os níveis de glicose sanguínea.

Os maiores níveis de glicose no tratamento 4 podem estar associados à maior quantidade da levedura influenciando no metabolismo dos carboidratos complexos presentes na palma transformando-os em açucares simples e que por excesso foram absorvidos pelas tilápias do Nilo aumentando a glicemia sanguínea. Entretanto, o valor encontrado no presente trabalho ainda se encontra na faixa ideal da homeostase da espécie avaliada, segundo Biswas et al. (2004), a tilápia do Nilo em situações de estresse apresenta valores de glicose na faixa de até $191,7 \mathrm{mg} / \mathrm{dL}$.

Maregoni et al. (2015), avaliando a influência de probiótico do gênero Bacillus no estado de saúde de juvenis de tilápias do Nilo em tanques-rede por meio do perfil bioquímico de glicose e a prevalência parasitárias nesses peixes, entretanto, os valores médios de glicose foram menores nos animais que receberam dieta com probiótico quando comparado aos que receberam a dieta controle, sugerindo que os peixes podem ter modificado sua homeostase para tentar se adaptar as parasitoses identificadas no estudo, o que justifica a similaridade da concentração do $\mathrm{T} 2: 2,5 \mathrm{mg} / \mathrm{kg}$ ao tratamento controle e ao tratamento T3: $2,5 \mathrm{mg} / \mathrm{kg}$, que proporcionou o menor nível de glicose, uma vez que os resultados das outras variáveis analisadas sugerem a incidência de estresse nos peixes.

\section{Conclusão}

Conclui-se que a inclusão de $5 \mathrm{mg} / \mathrm{kg}$ da levedura Saccharomyces boulardii liofilizada pode ser feita em dietas para tilápias do Nilo contendo palma, interferindo positivamente nos percentuais de trombócitos e linfócitos e mantendo os níveis de glicose dentro do recomendado para a espécie.

\section{Referências}

Araujo, D.M., Junior, A.C.F., Teixeira, C.P., Pezzato, L.E. \& Barros, M.M. (2015). Perfil hematológico de tilápias-do-Nilo alimentadas com dietas contendo diferentes lipídeos e estimuladas por baixa temperatura. Revista Caatinga, 28(1): 220-227.

Araújo, L.F., Silva, F.L.H., Brito, E.A., Oliveira júnior, S \& Santos, E.S. (2008). Enriquecimento proteico da palma forrageira com Saccharomyces cerevisiae para alimentação de ruminantes. Arq. Bras. Med. Vet. Zootec., 60(2): 401-407. DOI: http://dx.doi.org/10.1590/S010209352008000200019

Azevedo, R.V., Fosse Filho, J.C., Pereira, S.L., Andrade, D.R.\& Vidal Júnior, M.V. (2016). Prebiótico, probiótico e simbiótico para larvas de Trichogasterleeri (Bleeker, 1852, Perciformes, Osphronemidae). Arq. Bras. Med.Vet. Zootec., 68 (3): 795-804. DOI: http://dx.doi.org/10.1590/1678-4162-8580 
Azevedo, T.M.P., Martins, M.L., Yamashita, M.M. \& Francisco, C.J. (2006). Hematologia de Oreochromis niloticus: comparação entre peixes mantidos em piscicultura consorciada com suínos e pesque-pague no vale do rio Tijucas, Santa Catarina, Brasil. Bolm Inst. Pesca 32:4149.

Berra, J.A.P., Fiocco R.A., Ramos R.O. \& Ramos S.M. (1993) Técnicas para contagem global de glóbulos brancos em peixes. Bolm Téc. CEPTA 6:63-66.

Biswas, A., Masashi, M., Yoshizaki, G. \& Takeuchi, T. (2004). Physiological responses in Nile tilapia exposed to different photoperiod regimes. J Fish Biol, 65: 811-821.2004. DOI: https://doi.org/10.1111/j.0022-1112.2004.00487.x

Brito, J.M., Ferreira, A.H.C., Santana Júnior, H.A., Araripe, M.N.B.A., Lopes, J.A., Duarte, A.R., Barbosa Júnior, M.A. \& Silva, A.L. (2014). Policultivo de tilápias-do-Nilo (Oreochromis niloticus) e camarão marinho (Litopenaeus vannamei) em tanques-rede - Revisão. Revista eletrônica nutritime, 11(2): 3225-3237.

Cavalheiro, A.C.M. (2014). Microingredientes utilizados em alimentação de peixes em cativeiro Revisão. Revista Portuguesa de Ciências Veterinárias, 109(589-590): 11-20.

Costa, D.V., Ferreira, M.W., Navarro, R.D., Rosa, P.V. \& Murgas, L.D.S. (2014). Parâmetros hematológicos de tilápias-do-Nilo (Oreochromis niloticus) alimentadas com diferentes fontes de óleo. Rev. Bras. Saúde Prod. Anim., 15, (3):754-764.DOI: http://dx.doi.org/10.1590/S1519-99402014000300023.

Costa, L.F. (2004) Leveduras na nutrição animal. Revista Eletrônica Nutritime,1(1):01-06

Hannah, D.T.B., Cipriano, F.S., Lima, K. S, Allaman, I, B., Tonini, W.C.T., Takishita, S.S. \& Braga, L.G. T. (2016). Digestibility and performance of juvenile Nile tilapia fed with diets containing forage palm. Semina: Ciências Agrárias, 37(4): 2417-2426. DOI: http://dx.doi.org/10.5433/1679-0359.2016v37n4Supl1p2417

IBGE- Instituto Brasileiro de Geografia e Estatística. (2007). Censo Agropecuário. Obtido de: https://sidra.ibge.gov.br/tabela/6615

Jatobá, A. (2008) Utilização de bactérias ácido-lácticas isoladas do trato intestinal de tilápia-do-Nilo como probiótico. Pesq. agropec. bras.,43(9):1201-1207. DOI: http://dx.doi.org/10.1590/S0100-204X2008000900015

Kubitza, F. (1999). Nutrição e alimentação de tilápias parte - 1. Panorama da aquicultura, 9(52): 4250 .

Macedo,A.D.B.,Sousa,A.P.M.,Oliveira,J.A.M.,Mattos,M.A.,Santana,R.A.C.\&Campos,A.R.N.(2015 ). Bioconversão da palma forrageira e do sisal como alternativa para alimentação animal. Química: ciência, tecnologia e sociedade, 4(1): 88-98.

Marengoni, N.G, Weiss, L.A., Albuquerque, D.M. \& Moura, M.C. (2015). Influência de probióticos na prevalência parasitária e níveis de glicose e cortisol em tilápias do Nilo. Arch. Zootec. 64 (245): 63-69. DOI: https://doi.org/10.21071/az.v64i245.376

Matushima, E.R. \& Mariano, M. (1996). Kinetics of the inflammatory reaction induced by carrageen in in the swim bladder of Oreochromis niloticus (Nile tilapia). Braz. J. Vet. Res. Anim. Sci. 33:5-10.

Mundim, A.P.P. (2016). Indicadores hematológicos e bioquímicos do estresse em tilápias (Oreochromis niloticus), suplementadas com ractopamina. Archives of Veterinary Science. 21(2): 87-96. DOI: http://dx.doi.org/10.5380/avs.v21i1.44465

Pardo-Gamboa, B.S., Pinto, L.G.Q., Pezzato, L.E., Silva, F.A. \& Quintero-Pardo.A.M.C. (2011). Nutrientes digestíveis da levedura (Saccharomyces cerevisiae) íntegra e autolisada para Tilápia do Nilo (Oreochromis niloticus). Vet. zootec. 5(1): 26-38.

Pickering A.D. 1981. Stress and Fish. Academic Press, London 
Reque, V.R., Moraes, J.R.E., Belo, M.A.A. \& Moraes, F.R. (2010) Inflammation induced by inactivated Aeromonas hydrophila in Nile tilapia fed diets supplemented with Saccharomyces cerevisiae. Aquaculture,300: 37-42

Rijnberk, A. \& Mol, J.A. (1997). Adrenocortical function, p.533-568. In: Kaneko J.J., Harvey J.W.; Bruss M.L. (Eds), Clinical Biochemistry of Domestic Animal. San Diego: 5th ed. Academic Press.

Rosenfeld, G. (1947) Corânte pancrômico para hematologia e citologia clínica: nova combinação dos componentes do May-Grünwald e do Giemsa num só corante de emprego rápido. Memo. Inst. Butantan 20:329-334.

Sá, M.V.C. (2005). Limnocultura limnologia para aquicultura. Fortaleza: Editora da Universidade Federal do Ceará-UFC.

Santo,E.F.E.,Grassi,T.L.M.,Marcos,M.T.S.,Oliveira,D.L.,Cavazzan,J.F.,Ciarlini,P.C.,Narciso,L.G., Torres, A.A., Gonçalves,G.S., Abimorad,E.G. \& Ponsano, E.H.G. (2016). Desempenho, sanidade animal e qualidade de filés de tilápias alimentadas com ração suplementada com biomassa bacteriana. Arq. Bras. Med. Vet. Zootec., 68(2): 525-534.DOI: http://dx.doi.org/10.1590/1678-4162-7979

Schalch, S.H.C., Onaka, E.G., Fonseca, E.M., Garcia, F.S. Garcia, F. \& Castellani, D. (2015). Parâmetros hematológicos de tilápias (Oreochromis niloticus) alimentadas com dieta suplementada de cogumelo Agaricus blazei. Bioikos, 29(1): 9-34.

Silva, R.D., Rocha, L.O., Fortes, B.D.A., Vieira, D., \& Fioravanti, M.C.S. (2012). Parâmetros hematológicos e bioquímicos da tilápia-do-Nilo (Oreochromis niloticus L.) sob estresse por exposição ao ar. Pesq. Vet. Bras. 32(1): 99-107.DOI: https://doi.org/10.1590/S0100736X2012001300017

Signor, A., Pezzato, L.E., Falcon, D.R., Guimarães, I.G., Barros, M.M. (2010). Parâmetros hematológicos da Tilápia-do-Nilo: Efeito da dieta suplementada com levedura e zinco e do estímulo pelo frio. Ci. Anim. Bras., 11(3):509-519

Silveira, R \& Rigores, C. Caracteristicas hematologicas normales de Oreochromis aureus em cultivo. (1989) Rev. Latin. Am. Acuic., 39: 54-56.

Souza, R.B (2011) Utilização de leveduras de cana-de-açúcar (Saccharomyces cerevisiae) nas rações de aves. Revista Eletrônica Nutritime,08(06):1632-1646

Urbinati, E.C., Abreu, A.C.S.C. \& Parra, M.A.L. (2004). Loading and transport stress in juvenile matrinxã (Brycon cephalu) at various densities. Aquaculture, 229(1): 389-400.

Vidal, M.F. (2016). Panorama da piscicultura no Nordeste. Caderno Setorial Etene, 1(3): 13-19.

Wenderlaar Bonga, S.E. (1997) The stress response in fish. Physiol. Rev. 77:591-625 